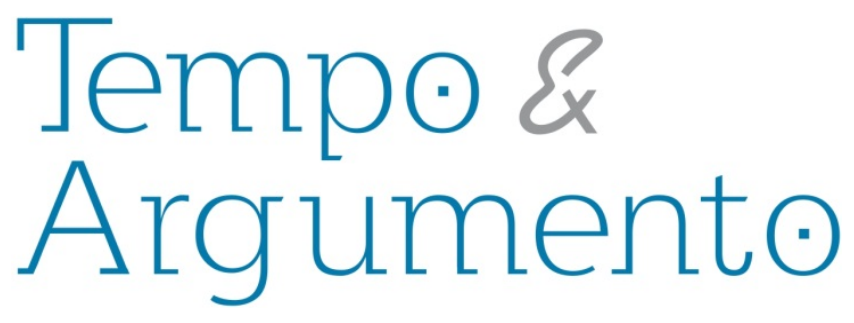

\title{
Domingo tem Abertura: um programa de televisão na cobertura da abertura política no Brasil ${ }^{1}$
}

\begin{abstract}
Resumo
O artigo analisa a constituição do programa Abertura, veiculado pela Rede Tupi, entre fevereiro de 1979 até maio de 1980. Trata-se de uma experiência de articulação política na TV ao discutir a abertura no exato momento em que esse processo ganhava maior espaço no início do governo do general João Baptista Figueiredo. $\mathrm{O}$ formato de revista, com uma equipe formada por Villas Bôas Corrêa, Sérgio Cabral, Fausto Wolf, Roberto D'avila, Ziraldo, Glauber Rocha e outros, inovou na linguagem ao propor uma reflexão jornalística audiovisual sobre as possibilidades do fim do regime civilmilitar. Muitos dos apresentadores estavam ligados ao pensamento de esquerda e discutiram questões importantes como anistia, exílio, censura, pluripartidarismo e eleições diretas para todos os níveis, contribuindo para o processo de luta democrática. A leitura do programa realizada pela imprensa escrita da época, e a constituição de uma autoimagem relacionada ao pioneirismo da iniciativa de lutar pela redemocratização do país na televisão conduzem a uma visão dicotômica, na qual se confrontaram a crítica de conteúdo e forma e a força do discurso do Abertura na tentativa de se firmar na memória política da mídia brasileira
\end{abstract}

Palavras-chave: Imprensa e Politica. Telejornalismo. Ditadura e Ditadores.

\section{Paulo Roberto de Azevedo Maia}

Doutor em História pela Universidade Federal Fluminense. Professor do departamento de história da Universidade Federal da Paraíba. João Pessoa, Paraíba - Brasil paulomaia@cchla.ufpb.br

\section{Para citar este artigo:}

MAIA, Paulo Roberto de Azevedo. Domingo tem Abertura: um programa de televisão na cobertura da abertura política no Brasil. Revista Tempo e Argumento, Florianópolis, v. 9, n. 21, p. 09 - 42. maio/ago. 2017.

DOI: $10.5965 / 2175180309212017009$

http://dx.doi.org/10.5965/2175180309212017009

\footnotetext{
${ }^{1}$ Este texto é uma versão modificada de parte do segundo capítulo de minha tese de doutorado, intitulada Abertura: televisão e a luta pela democracia no Brasil (1979-1980), defendida no Programa de pósgraduação em História da Universidade Federal Fluminense em 2014.
} 


\title{
Sunday has Abertura: a television program in the coverage of the process of political liberalization in Brazil
}

\begin{abstract}
The article analyzes the constitution of the opening program, broadcast by Rede Tupi, from February 1979 to May 1980. It is a political articulation of experience on TV to discuss the political openness at the very moment that this process gained more space at the beginning of the general João Baptista Figueiredo government. The magazine format, with a team of Villas Boas Correa, Sergio Cabral, Fausto Wolf, Roberto D'Avila, Ziraldo, Glauber Rocha and others, innovated the language to propose an audiovisual journalistic reflection on the possibilities of the end of the civil-regime military. Many of the presenters were linked to leftist thought and discussed important issues such as amnesty, exile, censorship, multi-party system and direct elections for all levels contributing to the democratic struggle process. The analyses of the program carried by the press and the establishment of a self-image related to the pioneering of the initiative to fight for the democratization of the country on television leads to a dichotomous vision in which the criticism of content and form and the force of the speech of the Abertura were confronted in the attempt to establish itself in the political memory of the Brazilian media.
\end{abstract}

Keywords: Press and Politics. Telejournalism. Dictatorship and Dictators.

\section{Introdução}

Em meio ao contexto de mudanças políticas do governo do presidente João Baptista Figueiredo, surgiu na TV Tupi o semanário Abertura ${ }^{2}$, o único voltado a discutir, como tema central, a abertura política na televisão brasileira. O programa foi resultado da ousadia do produtor de televisão Fernando Barbosa Lima e se estabeleceu com o pensamento de jornalistas e artistas, constituindo uma intelectualidade diversificada em

\footnotetext{
${ }^{2}$ Uma pequena parte do material do programa Abertura utilizado nessa pesquisa se encontra na Cinemateca Brasileira em São Paulo. A maior parte do material analisado está no Rio de Janeiro e pertence ao acervo pessoal de um dos diretores do programa, Carlos Alberto Vizeu. Apesar de o Abertura ter periodicidade semanal, as edições encontradas só apresentavam mês e ano, o que impossibilitou a sua referência exata.
} 
termos ideológicos e, apesar de ter sido um espaço de pluralismo de ideias, houve o predomínio da presença de personalidades de esquerda, que vivenciaram as transformações sociais, políticas e culturais das duas décadas anteriores.

O Brasil passou, nos anos 1970, por transformações importantes em uma década que começou com a afirmação do regime civil-militar na sua fase mais violenta e repressora, durante o governo do presidente Emílio Garrastazu Médici, e acabou em uma transição para a democracia, consolidada com o general João Baptista Figueiredo.

Com a posse do presidente Ernesto Geisel em 1974, o grupo de militares que estivera afastado do poder, desde o início do governo Costa e Silva, assumiu novamente o comando propondo mudanças sobre o destino político do Brasil. Os conflitos dentro do próprio governo se intensificaram entre os setores mais interessados na volta da ordem democrática e os conservadores, mais reticentes a uma brusca interrupção do regime. Isso provocou uma postura cautelosa de liberalização baseada na tese, anunciada desde a posse do presidente, de uma abertura "lenta, gradual e segura" (TELES; SAFATLE, 2015, p. 258). Entre avanços e retrocessos rumo à redemocratização, o país viveu a experiência da censura, da censura prévia e da autocensura acompanhada de tentativas, por parte de pessoas ligadas à mídia, de ocupar espaços para poder discutir questões relevantes que passaram a fazer parte da pauta da abertura política. Dessa forma, temas como a liberdade de expressão, a censura, a anistia e até mesmo as greves se tornaram recorrentes no final da década.

A análise do programa Abertura, proposta nesse artigo, pretende demonstrar como foi possível para um grupo heterogêneo discutir o processo de abertura política, revelando, através da pluralidade de pensamentos, as diferentes visões de uma perspectiva de redemocratização. Dessa forma, o tema da anistia política e a questão da censura são tratados. A imagem criada pela imprensa revela a importância do programa como uma voz pela democracia na televisão, mas apresenta críticas de conteúdo e forma. Por outro lado, houve o esforço do programa em criar uma autoimagem de instrumento da luta democrática que fosse duradoura na história. 
Para entender a constituição de um espaço voltado para discutir questões políticas na televisão no período da abertura, proponho pensar a TV, não como veículo de presença apenas de dominação ideológica, mas como produção cultural que tem intenções de tornar o seu discurso hegemônico na sociedade, o que não necessariamente acontece já que o telespectador tem a possibilidade de refletir sobre o que assiste. Sobre essa temática, vale a reflexão a respeito do pensamento de Stuart Hall. ${ }^{3}$

Stuart Hall problematizou os estudos sobre a televisão a partir da análise do fluxo televisivo que considera um conjunto no qual deve ser levado em consideração vários aspectos como a recepção, produção, circulação e a forma-mensagem para a formação de bens culturais. A codificação das mensagens televisivas está inserida numa estratégia de poder, na qual o produtor visa ter um poder hegemônico, mas que não pode ser visto como totalizante e definitivo, já que é "um tipo de sonho de poder - nenhum chuvisco na tela, apenas a audiência totalmente passiva" (HALL, 2003, p. 357). A intenção não deve ser vista como o resultado, o que leva a uma reflexão sobre a importância da decodificação da mensagem pois não existe apenas uma forma de recepção, ao contrário, essa pode acontecer de diversas maneiras, permitindo ao telespectador a possibilidade de concordar ou não com o que lhe é oferecido, o que depende muito em relação ao grupo de audiência em questão (PORTO, 2003). Trata-se de uma nova fase de estudos sobre as relações de poder ligados à mídia que contrariam a visão de dominação ideológica feita por Adorno, centrada no poder de manipulação da indústria cultural na "tentativa de incutir nas pessoas uma falsa consciência e um ocultamento da realidade, além de, como se costuma dizer tão bem, procurar-se impor às pessoas um conjunto de valores como se fossem dogmaticamente positivos" (ADORNO, 2001, p. 80).

O Abertura, ao propor trazer vozes plurais da direita e da esquerda, e tendo como tema central a abertura política, criou um ideal de hegemonia que se tornou, para alguns setores da sociedade, aceitável no conjunto da luta pela redemocratização, mas não determinante para a consolidação do processo de liberalização política, fenômeno muito mais complexo.

\footnotetext{
${ }^{3}$ Os estudos sobre comunicação da chamada "Cultural Studies", na Inglaterra da década de 1970, contou com Stuart Hall, o sociólogo Richard Hoggard, Raymond Willians e Eduard P. Thompson.
} 
Não é intenção desse artigo, ao analisar o programa Abertura, usar o conceito de fluxo televisivo em sua totalidade, mas dar ênfase na esfera da produção com sua preocupação na codificação, através de seu ideal hegemônico de afirmação da proposta de luta pela redemocratização, do discurso de pluralidade dos participantes e na afirmação de uma autoimagem de vanguarda democrática na televisão. O estudo da recepção é feito através das reações ao programa, em parte da imprensa escrita da época.

\section{O nascimento de um programa}

A televisão na década de 1970 ousou discutir temas ${ }^{4}$ e formatos em função das transformações históricas dentro do contexto político de uma ditadura que começava a indicar os primeiros sinais de mudança. O jornalismo começava a viver um período de possibilidades ampliadas de trabalho com o fim da censura prévia aos órgãos de imprensa, processo iniciado em 1975, com o fim da censura no jornal O Estado de São Paulo e fortalecido com a suspensão do Al-5 no final do governo de Ernesto Geisel em 1978. Esse foi o panorama que deu início a um projeto que marcou a volta de Fernando Barbosa Lima à televisão, afastado desde 1968 da produção de TV, quando começou a se dedicar à atividade publicitária com a criação da Esquire, agência de publicidade que se tornou uma das mais competitivas do Rio de Janeiro nos anos 1970 (LIMA, 2007, p. 91). A publicidade, embora fosse uma atividade rentável, não satisfazia o homem de televisão; era preciso voltar às origens e o momento se mostrava propício para investir em novas ideias.

\footnotetext{
Apesar de tudo, eu não conseguia esquecer a televisão e o jornalismo. A ditadura militar já estava no governo do general Figueiredo, que começou admitir a ideia de anistia, permitindo ao Brasil sonhar com a abertura política. Comecei, por minha vez, a vislumbrar a famosa luz no fim do túnel, a possibilidade de voltarmos a um estado democrático. (LIMA, 2007, p. 91)
}

\footnotetext{
${ }^{4}$ Seriados como Malu Mulher, discutindo a questão da mulher; Ciranda Cirandinha, mostrando o novo perfil do jovem brasileiro; Globo Repórter, mostrando problemas sociais com o trabalho de cineastas como Eduardo Coutinho e João Batista de Andrade.
} 
O governo do presidente João Baptista Figueiredo enfatizava o discurso próabertura, o que levou Fernando Barbosa Lima a apostar em uma ideia de programa semanal para discutir o processo político brasileiro na televisão. É verdade que a imprensa escrita já avançava nessa temática, publicando artigos de análise da política brasileira e discutindo as ações do governo, mas a televisão ainda mantinha cuidado na veiculação de discussões mais acaloradas e de opinião. Uma exceção foi o programa Vox Populi, ${ }^{5}$ transmitido desde 1977 e que trazia entrevistas com personalidades como Caetano Veloso, Chico Buarque, ${ }^{6}$ Nelson Rodrigues, Clarice Lispector e outros que puderam falar com liberdade, em um programa semanal, sobre os mais variados temas, inclusive questões relacionadas ao processo de abertura política. ${ }^{7}$ Mesmo assim, tanto a imprensa escrita quanto a televisão estavam longe de se concentrar no tema "abertura política" de forma sistemática; ele aparecia eventualmente no jornalismo, em programas de humor, seriados e novelas. A nova proposta procurava romper com o medo e o silêncio no meio televisivo de um tema que alcançou as ruas e prometia ser uma investida de cobrança e de fiscalização do governo, visando garantir que as medidas propostas não ficassem apenas no discurso, mas se concretizassem.

Uma produção ousada na temática, discutindo a abertura política era uma novidade passível de ser alvo de censura, o que poderia resultar em uma vida efêmera. A garantia de respaldo político para manter o programa no ar dependia, mesmo em tempos de liberalização, do aval das autoridades governamentais; para isso não bastava tomar contato com políticos locais, seria de grande proveito uma articulação junto ao primeiro escalão do governo. Pensando na viabilidade do programa, Fernando Barbosa Lima viajou

\footnotetext{
${ }^{5}$ Vox Populi, dirigido por Carlos Queiroz Telles e Roberto Muylaert, trazia perguntas do público para o entrevistado que não tinha conhecimento prévio das mesmas. Erasmo Dias, Caetano Veloso, Lula, Chico Buarque de Holanda, Clarice Lispector, Nelson Rodrigues foram algumas das personalidades entrevistadas no programa. Foi exibido pela TV Cultura de São Paulo, de 1978 até 1986. ALBUQUERQUE, Maria Elisa Vercesi de; AMORIN, Edgard Ribeiro de. TV Cultura: A concretização de um desafio. Entrevista com Roberto Muylaert. São Paulo, Revista D'art $\mathrm{n}^{\circ}$ 5, p. 57. Disponível em: <http://www.centrocultural.sp.gov.br/revista_dart/pdfs/dart12\%20tv\%20cultura\%20a\%20concretiza\%C3\%A7\% C3\%A30\%20de\%20um\%20desafio.pdf $>$. Acesso em: 02/02/2014.

${ }^{6}$ Os dois artistas passaram pela experiência do exílio. Caetano Veloso foi preso e exilado em 1969. Durante dois anos permaneceu em Londres, retornando em 1972. Chico Buarque de Holanda foi para a Itália com a família num autoexílio, que durou de 1969 a 1970, quando retornou ao Brasil.

${ }^{7}$ Em quatro programas assistidos, pude verificar que o tema Abertura Política esteve em todos. As entrevistas foram com Caetano Veloso (1978), Elis Regina (1979), Lula (1978) e Chico Buarque de Holanda (1979).
} 
para Brasília e, em uma audiência com o ministro da Justiça, Petrônio Portela, expôs suas ideias e a reação foi bastante positiva:

Mas o Fernando, aí pegou um avião e foi a Brasília conversar com o Petrônio Portela que era ministro da justiça nessa época. E falou para Petrônio: "Petrônio, ministro, eu estou com essa ideia de fazer esse programa. E o Petrônio que foi, pelo que eu conheço da história política, desse momento que eu vivi, foi um dos principais, se não o principal articulador e incentivador da abertura. Da volta da democracia ao país. E o Petrônio disse: "Oh, Fernando. Você acredita na abertura? Acredita ou não acredita?” Aí o Fernando disse: “Acredito!”. "Então se você acredita, bota seu programa no ar que ele vai ser um sucesso e ele vai ter todo apoio do presidente da república." Aí ele levou o Fernando ao Ludwig que era na época o principal homem de imprensa do presidente. E ele teve a mesma posição "bota no ar!". Aí o Fernando voltou já com o sinal. Me ligou. Naquela época eu tinha uma produtora de comerciais de televisão. Ele foi me procurar nessa produtora e disse "Vizeu, eu quero fazer o programa, mas eu não quero envolver a Esquire. Ela é uma agência de propaganda, não tem nada a ver com isso. Eu quero fazer esse programa com você e com o Loffler. O Loffler tinha acabado de sair da TV Globo. "Você topa? Vamos produzir o programa na sua produtora". "Eu topo. Acho ótimo". A ideia era muito boa. Eu fiquei muito entusiasmado com a proposta de fazer um programa assim. O Abertura era uma proposta muito boa. Desafiadora naquele momento. E aí o Fernando me chamou pra uma reunião na casa dele. Fizemos uma reunião lá e aí começou o processo de criação e produção do programa. ${ }^{8}$

Em seu livro de memórias, Fernando Barbosa Lima lembra o episódio e destaca a fala do ministro: "Fernando, se você não fizer esse programa é porque não acredita num Brasil democrático" (LIMA, 2007, p. 95). A frase era desafiadora naquele momento, mas, ao mesmo tempo, parecia a propaganda política de um regime que se esforçava para fazer valer um discurso de distensão ainda pouco consolidado em alguns setores do governo e da sociedade. Uma produção de televisão que se inicia com a permissão do governo gera dúvidas quanto as suas intenções e até mesmo sua legitimidade. Poderia ser questionado como um instrumento a serviço dos interesses do regime e não como um espaço de discussões amplo que realmente tivesse a ver com o espírito da abertura política. De qualquer forma, a fala do ministro ajudou a dar forças a uma ideia que precisava de aceitação com um incentivo oficial. Fernando Barbosa Lima havia se afastado da televisão pela impossibilidade de fazer jornalismo atuante como era o seu

\footnotetext{
${ }^{8}$ VIZEU, Carlos Alberto, Rio de Janeiro, 19/03/2011. Entrevista concedida a Paulo Roberto de Azevedo Maia.
} 

decretação do Al-5 e foi uma experiência de jornalismo diferente ao propor a participação dos jornalistas como produtores, cada um cuidando de seu próprio quadro. Newton Carlos, Villas-Boas Corrêa, Millôr Fernandes, João Saldanha ${ }^{9}$ entre outros. Era um grupo de profissionais vindos da imprensa escrita que começou a fazer televisão naquele momento. Os novos apresentadores levaram para a telinha, por orientação da produção, um novo formato, a crônica informativa. "O programa rompeu com a linguagem tradicional dos telejornais ao imprimir um tom coloquial ao discurso de seus apresentadores, em contraposição ao formalismo estabelecido até então". ${ }^{10}$ A audiência alcançada garantia ao programa uma posição de excelência durante toda a semana. $O$ destaque internacional veio da imprensa espanhola que concedeu o prêmio Ondas ${ }^{11}$ de melhor programa jornalístico do mundo em 1963. A forma diferenciada do telejornal apostou numa linguagem mais descontraída, obtendo o reconhecimento do meio jornalístico e, também, da academia, pois chamou a atenção de Marshall McLuhan que conseguiu uma cópia do programa e a utilizava em seu curso de comunicação na Universidade de Nova York (RESENDE, 2000, p. 106). Tendo passado por diversos canais, TV Continental, Tupi, Excelsior, Rede Globo e TV Rio, na qual o programa encontrou o seu fim ao ser retirado do ar definitivamente pela iniciativa do próprio diretor Fernando Barbosa Lima. O diretor chamou toda a equipe do programa e anunciou o seu fim, alegando que não era mais possível fazer um jornalismo autônomo. A presença constante de censores havia se tornado sistemática, impedindo a composição original de sua visão editorial. O Jornal de Vanguarda não deveria definhar até o momento em que não fosse mais possível fazê-lo. Era preciso encerrar suas atividades com dignidade, quando disse, então, a frase que se tornaria emblemática do fim do programa: "Cavalo de raça se mata com um tiro na cabeça." 12

\footnotetext{
${ }^{9}$ Com exceção de Millôr Fernandes, todos fizeram parte do programa Abertura.

${ }^{10}$ Memória Globo. Disponível em: <http://memoriaglobo.globo.com/Memoriaglobo/0,27723,GYNo-5273236474,00.html >. Acesso em: 06/06/2013.

${ }^{11} \mathrm{O}$ prêmio Ondas é concedido pela Radio Barcelona para os destaques de cada ano no rádio, televisão, cinema, propaganda e música.

12 Memória Globo. Disponível em: <http://memoriaglobo.globo.com/Memoriaglobo/0,27723,GYNo-5273236474,00.html >. Acesso em: 06/06/2013.
} 
Com a concordância de uma autoridade do primeiro escalão da presidência da República e de volta ao Rio de Janeiro, Fernando Barbosa Lima reuniu sua antiga equipe de televisão para expor o projeto e começar sua aplicação. Convidou Carlos Alberto Loffler, Carlos Alberto Vizeu e Luiz Carlos de Oliveira, homens experientes com produção de TV para participarem e, também, os jornalistas Carlos Rangel e Mário de Moraes. Os primeiros nomes apresentados traziam a preocupação de reunir uma equipe competente, avalizada pelos currículos, afinal, eram pessoas preparadas que haviam trabalhado nas principais emissoras do país, mas alguns deles, também eram dignos de confiança devido à experiência de trabalho com o diretor no Jornal de Vanguarda. A produção do programa ficou por conta da Teletape, produtora independente de vídeo de propriedade de Carlos Alberto Vizeu, que se tornou figura de expressão para a realização do projeto devido ao domínio técnico e engajamento na proposta de levar para a tela da televisão um programa diferente, mas principalmente, de intervenção na realidade social. ${ }^{13}$

Depois dos primeiros esboços de como o programa deveria ser, conseguir espaço na televisão foi o próximo passo para realização do projeto, o que se efetivou depois de uma conversa de Fernando Barbosa Lima com o Senador João de Medeiros Calmon, ${ }^{14}$ presidente da Rede Tupi: "Então o Fernando conversou com o Calmon e ele disse: 'Eu te dou um horário', naquela época tinha o programa do Flávio Cavalcanti aos domingos, 'depois do Flávio você entra'. Era uma hora e meia de programa."15

O programa ganhou o horário das vinte e duas e trinta até a meia noite, considerado bom pelo próprio produtor por permitir ganhar alguma audiência remanescente do programa anterior, Flávio Cavalcanti, grande sucesso de público durante os anos 1970, e por não entrar na mesma hora do Fantástico, da Rede Globo de Televisão, cujo horário de seu fim coincidia com o início do Abertura. A emissora escolhida para o programa era de cobertura nacional, mas com as mudanças promovidas pelo Ministério da Comunicação, aos poucos diminuía sua área de ação através de uma política de

\footnotetext{
13 VIZEU, Carlos Alberto, Rio de Janeiro, 19/03/2011. Entrevista concedida a Paulo Roberto de Azevedo Maia.

${ }^{14}$ Calmon havia assumido como Senador biônico em 1978, mas já tinha um histórico de trabalho dentro do grupo Associados de Chateaubriand, no qual começou como jornalista na década de 1940 e esteve à frente da Rede Tupi nos seus últimos anos de existência.

${ }^{15}$ VIZEU, Carlos Alberto, Rio de Janeiro, 19/03/2011. Entrevista concedida a Paulo Roberto de Azevedo Maia.
} 

em 1979 com a paralisação de 95\% de seus empregados. A venda de horário para empresas particulares era uma solução improvisada para garantir alguma receita e cobrir dívidas menores. Os problemas da Tupi eram atribuídos a uma administração desgastada com décadas de má gestão. Com a morte de Assis Chateaubriand, empresário que administrava de forma personalista e pouco profissional, a Tupi passou a ser controlada por um consórcio de 23 pessoas da confiança do falecido empresário, entre elas profissionais da emissora, políticos influentes e os seus filhos (SILVA, 2004). Esse condomínio não foi capaz de administrar a crise da Tupi; em 1980, os problemas se agravaram e, em maio daquele ano, nova greve paralisou a emissora que chegou a sair do ar durante horas e manifestações nas ruas e em frente à sede da Tupi demonstraram o descontentamento dos trabalhadores. A investida de Fernando Barbosa Lima começou com um problema anunciado, ou seja, o espaço televisivo não era garantido, e a qualquer instante a instabilidade da Tupi poderia prejudicar o programa, mas naquele momento, embora a crise da emissora fosse de conhecimento público, a Tupi parecia ser o único espaço disponível capaz de fazer valer o projeto.

Como em todo programa de televisão, a captação de recursos era uma questão relevante para garantir a viabilidade do empreendimento telejornalístico, mas no caso da Tupi, o problema era mais significativo porque:

Na Tupi muitas vezes uma estreia pode ser, também, a despedida de um programa. O experimentado Barbosa Lima tratou de se prevenir: conseguiu um patrocinador que se responsabiliza diretamente pelos salários e pelos custos de produção de toda equipe durante um ano. ${ }^{16}$

O patrocínio veio do contato com o jornalista e escritor Luis Lobo que na época era o diretor de comunicação da Associação Brasileira das Cadernetas de Poupança, órgão que reunia várias instituições financeiras de caráter privado. Ao saber da proposta do programa, Lobo confirmou o interesse da instituição em fazer parte do projeto (LIMA,

\footnotetext{
${ }^{16}$ VEJA, Agora é sério: A Tupi lança um novo jornal, São Paulo: 31/01/1979.
} 
2007, p. 96). O fato de não haver patrocínio estatal, conferia ao programa mais isenção, pois seria possível fazer um jornalismo, supostamente independente dos interesses do Estado. Se, politicamente, o patrocínio particular podia parecer como um ponto favorável à autonomia do programa e da equipe, em outra perspectiva, a financeira, parecia ser também positiva já que ter como financiadora uma empresa que era um "pool" de cadernetas de poupança era tudo o que programa precisava para iniciar seus trabalhos com a garantia de que seu cliente teria suporte financeiro para pagar sempre em dia e garantir sua viabilidade. A manutenção de um patrocínio exclusivo de empresas particulares não foi a realidade de todo o período em que o programa esteve no ar. Isso mudou com a presença de uma empresa de caráter estatal e fortemente identificada com o governo; a Caixa Econômica Federal tornou-se uma patrocinadora de destaque, passando a ter forte visibilidade como a primeira a aparecer, ainda na chamada inicial do Abertura. As edições analisadas do programa não indicam que o patrocinador de destaque tenha representado mudança na linha editorial do programa. Na medida em que o processo de liberalização avançava, o programa mais ajudava do que atrapalhava as intenções do governo. Ele, ao mesmo tempo, cobrava medidas liberalizantes e fazia propaganda.

\section{Construindo um programa}

Ao trabalharmos com um programa de televisão, devemos ter bem clara a especificidade do objeto dentro do contexto de empresa comercial que, como o próprio nome indica, tem interesses de mercado. A preocupação com a grade de programação se faz a partir das perspectivas de audiência. No caso específico do gênero jornalismo, é possível verificar que a informação pode ser vista como uma espécie de entretenimento e “qualquer que seja a categoria de um programa de televisão, ele deve sempre entreter e pode também informar. Pode ser informativo, mas deve também ser de entretenimento" (SOUZA, 2004. p. 51). Essa lógica está ligada aos interesses empresariais, o que implicou, ao longo da história da TV brasileira, no aparecimento de programas informativos que combinam entretenimento com informação. O programa Fantástico da Rede Globo de Televisão, que teve início em 5 de agosto de 1973, é um exemplo desse gênero televisivo. 

conceito de revista eletrônica que se firmava na TV brasileira (SOUZA, 2004. p. 51).

A exposição do pensamento político crítico ao regime começava a ser corriqueira na mídia impressa, mas a televisão, apesar de começar a se soltar em termos de conteúdo com programas como o Vox Populi, ainda tinha resistência das grandes redes. Deve-se levar em conta que a televisão, diferente dos jornais, era formada por concessões estatais, o que poderia criar expectativas negativas nos empresários do setor. O perigo de cassação dos direitos de transmissão era uma possibilidade real e nenhum empresário do setor queria se arriscar. Armando Nogueira, chefe de jornalismo da Rede Globo, afirma que mesmo o período de abertura política contando com uma censura menor, a televisão criava mecanismos de autocensura para proteger a empresa de possíveis “constrangimentos”. Com essa preocupação, a equipe de jornalismo da Globo enfatizava a forma e não o conteúdo em virtude dos cuidados que deveriam ser tomados com o período que não era de total liberdade:

Foi essa implacável marcação da ditadura que nos levou a esquecer da batalha do conteúdo para tentar descobrir os encantos da forma nesse veículo. Trabalhávamos em cima da técnica e da estética, deixando de lado, um pouco, a ética de fazer jornalismo. (NOGUEIRA apud RESENDE, 2000, p. 119)

O Abertura era uma aposta em um programa de conteúdo, tinha uma temática definida e pessoas envolvidas com entusiasmo para romper o silêncio. O investimento no conteúdo não abandonou a preocupação com a forma, apesar dos poucos recursos técnicos, foi desenvolvido um estilo próprio de jornalismo ancorado na ideia de uma revista de variedade, mas diferente da proposta do Fantástico da Rede Globo. Fernando Barbosa Lima, segundo Carlos Alberto Vizeu, não estava preocupado em fazer uma revista de televisão com quadros fixos. Não seria necessário manter, semanalmente, uma sequência rígida de apresentadores e quadros musicais obrigatórios. A direção não primava pelo equilíbrio das cenas e não exigia de sua equipe um comportamento padrão. 
Eles deveriam, cada qual no seu momento, discutir um problema ligado à realidade do país ou do mundo, sem ter o foco exclusivamente na política, já que a proposta era trazer pessoas de diversos ramos para pensar o país, mas não dentro dos esquemas tradicionais. O diferente, o pouco provável e o curioso estavam na televisão aos domingos à noite com a presença de pessoas, imagens, sons que transgrediam os limites impostos por um governo ditatorial, não no plano do discurso político que era provocativo, mas assimilável devido à concessão dada pelo governo. Uma grande transgressão era de caráter linguístico e estético. A questão não se resumia ao que dizer, uma vez que as intenções do programa naquele contexto eram claras, mas como dizer. A narrativa dos apresentadores de telejornais com a sobriedade que lhes era peculiar e com uma fala pouco expressiva advinda dos teleprontos, sem criticidade, apenas levando ao telespectador a informação sem opinião, sem o posicionamento, ou ainda, defendendo uma posição patronal, sem vinculo com o pensamento do narrador como o que pode ser verificado nos eventuais editoriais. Fazer um jornalismo crítico, de opinião, aberto a personalidades de diferentes tendências ideológicas de diversas áreas, eis o desafio para romper com o tradicionalismo. A solução não poderia ser encontrada no passado, a televisão deveria demarcar a transição que o país estava passando, recorrer aos velhos estilos de jornalismo não daria conta de mostrar a dinâmica de uma nova sociedade com liberdade que estava por nascer; no entanto, fazer uso apenas do novo não iria garantir a identidade histórica capaz de fazer com que houvesse reconhecimento popular. Nem o novo radical, nem o conservadorismo das velhas práticas, mas a junção dos dois, resgatando o melhor do Jornal de Vanguarda com a colaboração de apresentadores vindos dos mais variados meios (atores, atrizes, jornalistas, intelectuais, esportistas, cineastas) gente de televisão ou não. O novo seria a criação de uma revista na qual a entrevista, a crônica, o comentário da notícia da semana, levassem a uma reflexão sobre o Brasil, mas diferente do que acontecia no Fantástico, a busca pela audiência não seria o fio condutor do programa. Não deveria valer tudo porque a intenção primeira de Fernando Barbosa Lima era promover a discussão da vida política do país: 
O Fernando não tinha preocupação de ter um musical. A preocupação do Abertura era com o resgate da vida política do país. A preocupação do Fernando era essa. Não tinha outra. Então, todas as pessoas que estavam ali era porque tinham o que dizer. Não tinha essa preocupação de "eu vou botar isso porque dá um equilíbrio para o programa. Ah, não vou botar um musical porque se não vai desequilibrar". Não tinha. ${ }^{17}$

Embora Carlos Alberto Vizeu tenha afirmado que não havia uma preocupação maior com a harmonia do programa, o que podemos ver é uma variedade de quadros, inclusive musicais, mas uma novidade era a presença de figuras não habituadas com o ambiente da televisão, como o fotógrafo Antônio Guerreiro, responsável por um quadro com a apresentação de modelos sendo fotografadas e entrevistadas. A variedade de quadros garantia uma dinâmica maior, facilitando a composição de imagens que, embora não reconhecida, ajudava numa composição harmoniosa, não de um equilíbrio de gêneros, mas de assuntos abordados e propostas narrativas diferenciadas.

Paula Serra, em seu artigo "Estética e media - o caso da televisão" (SERRA, 2012), recupera a análise de Ernst Gombrich sobre a aproximação entre a arte clássica e a "indústria do entretenimento" e afirma que toda vez que existe na obra audiovisual a intenção de levar um determinado tema sob a ótica do realismo, isso produz uma reação, fazendo com que as pessoas sejam cativadas pelo inesperado e pelo real, assim:

Produzir um realismo que "surpreenda" e "cative" será, assim, um objetivo comum à arte clássica e à indústria do entretenimento contemporâneo e, mais especificamente, ao audiovisual ou, para sermos mais precisos, um objetivo que se terá transferido da arte para o audiovisual. (SERRA, 2012)

Longe de querer atribuir ao Abertura o caráter de obra de arte, mas admitindo a existência de componentes artísticos em sua produção, é possível afirmar que a discussão política proposta foi capaz de criar uma realidade que estava vinculada à leitura do Brasil feita pelos articulistas ou pelos entrevistados. O resultado foi um produto audiovisual capaz de chamar a atenção do telespectador por discutir os temas da atualidade política, literária, cinematográfica em padrões que fogem do convencional e revelam uma nova

\footnotetext{
${ }^{17}$ VIZEU, Carlos Alberto, Rio de Janeiro, 19/03/2011. Entrevista concedida a Paulo Roberto de Azevedo Maia.
} 
perspectiva da produção jornalística de televisão. A forma solta e descontraída criava um anti-padrão Globo de qualidade, que não se amparava nos recursos técnicos, mas na habilidade dos câmeras e na direção artística. O grande responsável pela exploração estética das imagens era Carlos Alberto Loffler, minucioso na condução dos planos e ângulos, produzindo efeitos visuais impensados com apenas uma câmera que era o único recurso que programa tinha. Isso dificultava, principalmente nas filmagens externas onde havia o apelo visual, a captação de imagens sob diferentes ângulos. Essa limitação técnica reduzia as possibilidades da montagem. ${ }^{18}$

O espaço era um componente diferenciador do Abertura já que ele era gravado quase totalmente fora do estúdio, que era utilizado apenas para a apresentação e para comentários. Os quadros eram feitos nas casas, apartamentos e locações externas a critério de cada apresentador. Cada um tinha autonomia para realizar a sua parte utilizando os recursos que achasse necessários, bem como o local mais propício. Alguns lugares foram inusitados, como a entrevista que Tarcísio Holanda, repórter de política em Brasília, fez com o então ministro da Previdência Social, Jarbas Passarinho, no interior de uma limusine conversível. ${ }^{19}$

A dinâmica de trabalho do programa contava com filmagens realizadas ao longo da semana com a equipe formada por um motorista, um cinegrafista e um diretor, necessariamente, Carlos Alberto Vizeu ou Carlos Alberto Loffler. Enquanto um estava realizando a produção de um quadro, o outro estava se ocupando de outra atividade, pois não era possível filmagens simultâneas devido à precariedade da produtora Teletape, que garantia apenas uma câmera para realizar todos os quadros.

A composição imagética garantia uma estética ${ }^{20}$ diferenciada de outros programas jornalísticos. A diversificação de propostas de pensamento atrelada a um senso histórico que impunha a necessidade de transformações era uma inovação do Abertura, pois a

\footnotetext{
${ }^{18}$ VIZEU, Carlos Alberto, Rio de Janeiro, 19/03/2011. Entrevista concedida a Paulo Roberto de Azevedo Maia.

${ }^{19}$ Programa Abertura, Rede Tupi, Tarcísio Holanda, março de 1979, Rio de Janeiro.

${ }^{20}$ A definição de estética adotada está de acordo com a etimologia da palavra, derivada de aisthesis, sensação que se refere à sensibilidade, à capacidade que certas criações humanas têm de chamar a nossa atenção e produzir em nós um determinado conjunto de "sensações" especiais a que chamamos "beleza”; que, por conseguinte, não existe “em si”, mas apenas “para nós”, isto é, como experiência que nos atinge.
} 
exploração de imagens conciliava as preocupações da realidade do contexto histórico do período com a exaltação da memória recente do país, como podemos verificar na abertura do programa: “Atenção Rede Tupi de Televisão, atenção Embratel, ligação direta com todo o Brasil."21 Uma voz feminina anunciava que o programa Abertura estava prestes a começar. A câmera fechava na imagem de um olho desenhado numa parede. Funcionava em sua íris um marcador de contagem regressiva. A cada segundo mostrado, intercalava o nome do patrocinador "Caixa Econômica Federal". Ao zerar a contagem, surgia a chamada das principais atrações, seguida de um breve editorial com duração de aproximadamente dois minutos. A abertura é concluída com uma vinheta que apresentava uma série de fotos de personalidades da política, dos esportes, da literatura e da música. Ela iniciava com o som de tambor, sem música, anunciando a imagem de Getúlio Vargas, Juscelino Kubitschek e, ao fundo, o som de uma máquina de escrever apontava, metaforicamente, para a liberdade de imprensa; as imagens continuavam a se suceder com Jânio Quadros, João Goulart, Castelo Branco, Costa e Silva, Garrastazu Médici, Ernesto Geisel e João Figueiredo. A ordem dos presidentes era cronológica e, ao finalizar a imagem do último presidente, surgia o anúncio "A Rede Tupi de televisão apresenta ABERTURA". O som da máquina de escrever acelerava e as imagens ressurgiam numa velocidade bem maior, trazendo outras personalidades do contexto histórico da época como Chico Buarque, Carlos Drummond de Andrade, Magalhães Pinto, Antônio Carlos Magalhães, Ulisses Guimarães, Paulo Maluf, Oscar Niemeyer, Vinicius de Moraes, Delfin Neto, Ibrahim Sued, Nelson Rodrigues, Pelé, Tom Jobim, Tancredo Neves, Roberto Marinho, Emerson Fittipaldi, Jarbas Passarinho, Orestes Quércia, Nelson Marchesan, Aureliano Chaves, Marco Maciel, Roberto Carlos, Darcy Ribeiro, Coronel Erasmo Dias e outros nomes importantes da política, dos esportes e das artes.

A composição de imagens da vinheta inicial é uma leitura da história recente do país na qual o passado é invocado através das imagens dos presidentes Getúlio Vargas, Juscelino Kubitschek, Jânio Quadros e João Goulart. A mera exposição das figuras presidenciais já enuncia a trajetória do populismo no Brasil. Não existia nenhuma referência à ruptura política que representou o golpe de 1964 e os presidentes militares

\footnotetext{
${ }^{21}$ Programa Abertura, Rede Tupi, março de 1979, Rio de Janeiro.
} 
em comum. O sorriso no rosto simbolizava a nova fase do processo de distensão. As imagens seguintes ao anúncio do título do programa avançam no sentido de mostrar a ruptura com o passado já que a dinâmica das imagens que mudam com velocidade muito superior daquelas iniciais, remete à transformação da sociedade com o processo de abertura política. Era uma aposta nas mudanças que estavam ocorrendo e nas que viriam depois, refletindo o próprio significado do programa. A pluralidade de pensamento é outra característica da vinheta que mostra figuras das mais variadas tendências políticas. Um exemplo é a figura de Erasmo Dias, coronel reformado da polícia militar paulista, secretário de Segurança Pública do Estado de São Paulo no governo de Laudo Natel (19711975), cargo que manteve ao longo do governo seguinte, de Paulo Egídio Martins, até 1978. Ele ficou famoso por comandar a tropa de choque, em setembro de 1977, na invasão do campus da PUC de São Paulo com o objetivo de evitar o III Encontro Nacional de Estudantes, movimento organizado pela União Nacional dos Estudantes (UNE). A repressão se deu de forma violenta com a prisão de cerca de 90 pessoas e graves queimaduras em quatro estudantes devido a bombas de gás lacrimogêneo (CARMO, 2000, p. 133). Sua imagem convivia, na vinheta de abertura do programa, com a foto do poeta Vinicius de Moraes. A imagem do autoritarismo ao lado do lúdico e romântico "poetinha vagabundo".

Todo o conjunto imagético formado com as fotos das personalidades era finalizado com o narrador pronunciando a seguinte frase: “Quem poupa, conquista o que a vida tem de melhor", mensagem da Caixa Econômica Federal e de todo o pool de empresas do setor que financiavam o programa, mas também do governo que tinha o fortalecimento da poupança nacional como uma de suas prioridades na economia. 


\section{Anistia}

O apresentador João Saldanha fez de seu quadro um espaço de reivindicação. Pediu anistia para Nelson Rodrigues Filho. O filho do escritor Nelson Rodrigues participou da luta armada e foi condenado a 70 anos de prisão durante o governo Médici. O apelo de Saldanha afirmava o repúdio pelo terrorismo que só poderia ser aceito na luta contra um invasor do território nacional e nunca contra o seu próprio país. A crítica inicial deu lugar ao reconhecimento da coragem do rapaz que não aceitou ir para o exílio sem seus companheiros. Em tom enfático, pediu sua libertação e acrescentou: "Anistia se não for total, anistia se não for esquecimento, anistia se não representar perdão, anistia deixa margem de revanche, de forra, de vingança, de vendeta como diria o siciliano. É por isso que o Abertura pede anistia." ${ }^{22}$

A partir do governo Geisel, com a ideia de distensão política propagada, o pensamento sobre anistia começou a existir como possibilidade real. Em 1977, enquanto o governo adotava medidas para evitar o avanço da oposição com o que ficou conhecido como "Pacote de Abril", criando o cargo de Senador Biônico que garantia uma cadeira do Senado para o governo em cada Estado da nação, começaram as manifestações de rua de estudantes contra prisões e tortura de presos políticos (REIS FILHO, 2002, p. 68). O movimento que lutava pela redemocratização do país, logo depois se integrou à luta pela anistia política. Espalharam-se pelo país organizações de direitos humanos e a anistia passou a fazer parte de seus ideários de luta, ideia válida, também, para os grupos progressistas ligados à Igreja Católica como a Comissão de Justiça e Paz e as Comunidades Eclesiais de Base (CEBs) e até mesmo, organizações de Igrejas Protestantes, tendo o exemplo do Colégio Episcopal da Igreja Metodista (MEZAROBBA, 2006, p. 28). Em 1978, advogados, familiares e amigos de presos e exilados políticos criaram o Comitê Brasileiro de Anistia, com o intuito de organizar as ações em favor da causa. Com a pressão dos movimentos populares, o presidente Geisel iniciou um diálogo com instituições representativas da luta democrática como a Ordem dos Advogados do Brasil (OAB), a Associação Brasileira de Imprensa (AIB), a Confederação Nacional dos Bispos do Brasil (CNBB), além de políticos da oposição ligados ao MDB. A discussão

\footnotetext{
${ }^{22}$ Programa Abertura, Rede Tupi, João Saldanha, Rio de Janeiro, abril de 1979.
} 
travada com esses setores da sociedade levaria o governo à formulação, em 1978, da emenda constitucional $\mathrm{n}^{\circ} 11$ e, a partir dela, era revogado o artigo 182 da constituição de 1969, acabando com o Al-5. Essa medida, ao retirar o país do clima de repressão extrema, viabilizou a proposta de anistia política (RIBEIRO, 2005, p. 40).

O debate sobre a anistia ganhou força com o início do governo Figueiredo que defendia o processo de abertura e o fim das retaliações aos chamados "subversivos". Essa medida era importante por ser uma concessão em resposta aos movimentos populares. Era imperativo melhorar a imagem do governo junto à sociedade, assim como não era mais possível ignorar as passeatas, debates, comícios e a pressão no Congresso Nacional pela criação de um projeto de lei que fizesse a anistia, promovendo a volta dos exilados ao Brasil.

A questão da anistia se tornara um problema de dimensão internacional e a imprensa escrita já promovia discussões e especulações sobre se o governo tinha intenção de fazê-la de fato; para isso, traziam a opinião dos mais diversos personagens da vida política nacional para se posicionarem; de políticos da oposição e do governo até representantes de organizações da sociedade civil, mas a televisão, o grande meio de comunicação de massa, estava ausente na divulgação sistemática de informações sobre o andamento da discussão. O Abertura elegeu esse tema como primordial e já no primeiro programa, em 4 de fevereiro de 1979, vários foram os momentos em que a questão foi abordada. A entrevista de Tarcísio Holanda com o ministro da justiça, Petrônio Portela, demonstra a disposição dos participantes do programa em abordar um ponto delicado, mas que já fazia parte da pauta de mudanças pretendidas pelo governo. O presidente Figueiredo já havia anunciado, antes mesmo das eleições que o consagraram o substituto de Ernesto Geisel, que era sensível à anistia e que tinha intenções de fazê-la. Ao indagar se eram realmente sinceras as intenções do governo em relação à anistia, Tarcísio Holanda o fez de forma muito provocativa: "O presidente Figueiredo pretende realmente fazer a anistia ou isso é mais uma balela do governo?"23 O ministro irritado com a forma como foi feita a pergunta responde que sim, a anistia era uma prioridade e que iria acontecer. O questionamento prossegue com a iniciativa do repórter de, novamente,

\footnotetext{
${ }^{23}$ Programa Abertura, Rede Tupi, Tarcísio Holanda, Rio de Janeiro, fevereiro de 1979.
} 
questionar a veracidade da informação fazendo comentários sobre o pacote de abril e sobre como o governo tentou criar mecanismos de controle do processo eleitoral. $\mathrm{O}$ ministro insistiu afirmando que ele próprio estava empenhado no projeto de lei que seria levado ao congresso nacional para ser discutido e aprovado. Chama a atenção o fato de que o entrevistado era o "padrinho" político do programa, já que a forma como a entrevista foi conduzida revela a intenção de apresentar, na edição número um, a autonomia do elenco de apresentadores afinados com os problemas brasileiros e desvinculados do governo. A estratégia, apesar de aparentemente submeter um membro do alto escalão do governo a uma situação vexatória, foi também a oportunidade do próprio governo de se manifestar, deixando a impressão de que a indignação do ministro com as afirmações do apresentador eram mais uma prova de que o governo Figueiredo levaria adiante a anistia.

A campanha pela anistia crescia no Brasil, mas no exterior havia uma grande expectativa pela aprovação de uma lei que, de fato, garantisse segurança para todos que sentiram a repressão e viviam no exterior. O Abertura, como defensor da proposta da anistia, discutiu a questão do exílio.

O quadro de Roberto D'avila apresentava a esperança dos exilados na volta ao Brasil, perspectiva que era trazida pelas discussões em torno da ideia de criação da lei da anistia. Apesar da diversidade de nomes que foram entrevistados, existe o predomínio de personalidades ligadas à primeira geração de refugiados, uma explicação para isso está na própria trajetória de vida de D'avila que foi para França estudar história e jornalismo e se identificou com os brasileiros exilados em Paris, passando a manter amizade com vários deles. Uma figura, em particular, que teve presença forte no quadro, foi Leonel Brizola. Aliado do político gaúcho, D'avila levou ao ar algumas entrevistas em Lisboa e Paris, que já anunciavam suas ideais de retornar ao Brasil e recuperar a legenda do PTB, acreditando na redemocratização com a volta dos partidos. Era o otimismo gerado pelas discussões em torno da lei da anistia feita por pessoas que esperavam por transformações com as quais não podiam colaborar de forma efetiva, aliás, o papel dos exilados foi motivo de discussão nos movimentos de esquerda, pelo menos para geração de 1968, na primeira fase do exílio. Acreditava-se que não deveria haver intervenção nos 
processos de luta daqueles que não estavam vivendo no Brasil. Qualquer interferência não era vista como válida, cabendo a ação apenas aos militantes que estavam no país, contribuindo para a prática revolucionária na luta contra a ditadura, o comando e as decisões dos movimentos. A tarefa dos exilados era esperar pela orientação. Essa divisão de papéis ficou conhecida como o "Mito da Terra" (ROLLEMBERG, 1999), que acabou por separar o movimento entre os que lutavam e aqueles que ficavam na teoria, no debate, fora da prática. Os exilados mantiveram o debate como forma de manter viva a ideia de luta política, não necessariamente revolucionária, o que é possível verificar em publicações de esquerda no exterior como a revista Brasil socialista, publicada em Paris. A publicação entrava clandestinamente no Brasil e circulava entre os militantes de esquerda de grupos revolucionários e do movimento estudantil. A revista teve particular importância na discussão sobre a autoavaliação da luta armada e a opção pela luta democrática (ARAÚJO, 2004, p. 163). Com o desejo de se manifestar, um pequeno grupo de brasileiros teve, no trabalho de D'avila, a oportunidade de expressão no meio televisivo, o que era, até então, inédito em termos de espaço de manifestação.

A solidão, o estranhamento cultural, o preconceito, a luta pela sobrevivência, a infantilização foram alguns dos problemas vividos por brasileiros em vários países europeus. A experiência do exílio, longe do romantismo que poderia inspirar, representou, para uma parcela das pessoas que viveram fora do país de forma compulsória, um período de dor e medo (ARAÚJO, 2004, p. 163). As entrevistas de Roberto D'avila mostravam depoimentos otimistas, mas traziam o lado mais dramático de quem viveu as dificuldades do exílio. Muitas foram as entrevistas, mas a que teve maior repercussão foi a de um grupo de crianças, filhas de exilados que falavam como era viver na Europa sem conhecer o país em que nasceram e, também, relatavam as esperanças, ligadas aos interesses de seus pais, de voltarem ao Brasil. Em tom emocional, as crianças, com seus relatos, faziam um apelo para que o governo levasse adiante o processo da anistia política "ampla, geral e irrestrita". ${ }^{24}$ Era o desabafo de quem teve que abandonar seu país por conta da repressão sofrida pelos pais, sem terem feito nada que justificasse seu banimento.

\footnotetext{
${ }^{24}$ Programa Abertura, Rede Tupi, Roberto D'avila, Rio de Janeiro, junho de 1979.
} 
Da mesma forma que o programa exaltava a necessidade de se fazer a anistia, ele também mostrava a resistência por parte de setores políticos conservadores que repudiavam essa ideia. Em entrevista com o deputado da ARENA, Erasmo Dias, a intolerância e o apego à questão ideológica anticomunista estavam presentes no discurso. Ao ser indagado se a anistia deveria ser concedida a Leonel Brizola, Miguel Arraes, Luís Carlos Prestes e outros, o deputado respondeu:

Todos aqueles responsáveis pelo estado de anarquia de 1963/1964. Os membros do Partido Comunista e que defenderam através da luta armada a subversão do nosso regime. Eu, em absoluto, não posso concordar com anistia para essa gente. ${ }^{25}$

A fala do então governador da Bahia, Antonio Carlos Magalhães, demonstra o interesse em se fazer um perdão de caráter político, mas que ao se preocupar em deixar de fora a ideia de ser um ato irrestrito, poderia levar a uma anistia limitada se sequestros e assaltos a bancos feitos com motivação política fossem definidos como crimes comuns.

Eu acho que a anistia no campo político deve ser a mais ampla possível, agora, infelizmente ela não pode ser irrestrita até para que não se confunda os políticos com outros que estão, realmente, em outros crimes que não são de natureza política. ${ }^{26}$

O posicionamento conservador dos deputados era contrastado pela fala de Tarcísio Holanda em defesa da anistia ampla e não excludente como era a vontade do governo. "Sendo um gesto de grandeza, a anistia não pode discriminar pessoas. Não pode isolá-las, não pode excluí-las. Essa é uma afirmação que o ministro da justiça tem feito a todo momento." 27

A anistia se concretizou com a aprovação pelo Congresso Nacional da lei $n^{\circ} 6.683$, que foi promulgada pelo presidente Figueiredo em de 28 de agosto de 1979. A partir daí, foi possível a volta de brasileiros que se encontravam no exterior. O programa Abertura não só mostrou a chegada dos exilados, como fez a imprensa em geral, mas tratou de

\footnotetext{
${ }^{25}$ Programa Abertura, Rede Tupi, Tarcísio Holanda, Rio de Janeiro, maio de 1979.

${ }^{26}$ Programa Abertura, Rede Tupi, Glauber Rocha, Rio de Janeiro, outubro de 1979.

${ }^{27}$ Programa Abertura, Rede Tupi, Tarcísio Holanda, Rio de Janeiro, março de 1979.
} 
trazer os discursos para a televisão. Começou uma série de entrevistas que mostravam a alegria da volta à terra e a esperança na redemocratização do país. Darcy Ribeiro, Miguel Arraes, Leonel Brizola e Luís Carlos Prestes foram alguns dos entrevistados. Em geral, os discursos estavam direcionados à reconstrução do quadro partidário, modificado radicalmente pelo ato institucional $\mathrm{n}^{\circ} 2$, limitando, na prática, a existência de apenas dois partidos. Existia uma expectativa muito grande pela volta das eleições diretas em todos os níveis.

\section{Censura}

A televisão, mesmo em tempos de abertura política, sofreu com restrições impostas pelo governo. No caso do Abertura, o programa conseguiu passar toda sua existência sem sofrer a repressão da censura e, segundo Fernando Barbosa Lima, isso se devia à atitude pessoal do ministro da justiça Petrônio Portela: "Jamais ocorreu nenhum tipo de censura, nem minha, nem do governo, nem da Tupi. E devo isso ao ministro Portela, uma verdadeira barreira entre nós e o SNI, entre nós e a direita radical, entre nós e os generais" (LIMA, 2007, p. 96).

Com a garantia de um "protetor" do alto escalão do governo, o programa pôde discutir a censura em diversos quadros. O jornalismo político do Abertura teve, na entrevista realizada com o senador arenista, Jarbas Passarinho, pelo correspondente Tarcísio Holanda, um momento inusitado. Dentro de uma Limusine conversível, entrevistado e entrevistador circularam pelos principais pontos políticos da capital federal. O assunto em pauta foi a censura, tema privilegiado acerca do qual Passarinho defendeu a ideia de que o abrandamento desta poderia acontecer, mas em hipótese alguma o Brasil deveria acabar com ela, pois esse seria um recurso utilizado em todo o mundo para defender a própria sociedade. Os questionamentos políticos ganharam um contorno de caráter estético, pois a composição da entrevista era dirigida pela trajetória do automóvel, assim, ao questionar sobre a validade da abertura política, o automóvel para e surge, ao fundo, a imagem do Palácio do Planalto numa alusão ao poder e sua responsabilidade numa possível redemocratização. Para finalizar a entrevista, uma pergunta com tom de ironia: "No futuro, o senhor vai ter coragem de dizer para os seus 
Em maio de 1980, o presidente da comissão de comunicações da câmara dos deputados, o deputado Israel Dias Novaes, do MDB, organizou um simpósio para discutir a questão da censura e tentar fazer um mapeamento da ação repressiva do governo. Convidou figuras expressivas da televisão, cinema, teatro e da imprensa para darem seus depoimentos e fomentarem a discussão sobre a censura. O jornalista Tarcísio Holanda fez a cobertura do simpósio e entrevistou o deputado que defendeu o encontro como sendo o estudo do "processo da censura no Brasil, através desse processo nós chegaríamos à verificação do fenômeno e os meios de corrigi-los."29 Entre os convidados do evento estava o teatrólogo Plínio Marcos que foi a Brasília para criticar a ação do Estado:

A censura é um braço do coronelismo cultural que vem permitindo a invasão da cultura de consumo nos nossos veículos de comunicação social e isso tem provocado essa massa enorme, o empobrecimento do povo brasileiro, alienando, fazendo com que ele não perceba que está marginalizado da sua própria história, impedido de influir no próprio destino. ${ }^{30}$

O deputado Israel Dias Novaes concluiu que a censura feita pelo Estado, de forma repressora, deveria acabar, dando lugar a um Conselho Nacional que iria estabelecer um sistema classificatório. Esse seria o primeiro passo para se atingir o que considerou o desejo daqueles que participaram do evento, uma "censura feita pelo próprio povo". A conclusão do deputado apresentou-se de forma muito genérica e não foi consenso. Ao mostrar a fala de Novaes e sua justificativa para criar um sistema de censura desvinculado das questões políticas, mas voltado para a moral, com a participação popular, o programa, através da montagem, estabeleceu um paralelo da fala do parlamentar com a de Plínio Marcos que discordou de sua posição, afirmando que "Censura é sempre censura. Censura é polícia, é repressão."131

\footnotetext{
${ }^{28}$ Programa Abertura, Rede Tupi, Tarcísio Holanda, Rio de Janeiro, março de 1979.

29 Programa Abertura, Rede Tupi, Tarcísio Holanda, Rio de Janeiro, março de 1980.

30 Programa Abertura, Rede Tupi, Tarcísio Holanda, Rio de Janeiro, março de 1980.

31 Programa Abertura, Rede Tupi, Tarcísio Holanda, Rio de Janeiro, março de 1980.
} 


\section{Pensando o Abertura}

O Abertura procurou se impor no fortalecimento do imaginário de redemocratização do Brasil e teve importância, não por criar as condições para a formação de um público favorável às ideias democráticas, mas por reforçar uma tendência já manifesta nas iniciativas do governo de propor a abertura, e da sociedade, por meio das manifestações contra o regime. É mais um elemento de reforço à luta democrática. Dessa forma, a atuação desse veículo na manipulação de símbolos pode ser vista sob a perspectiva de Bazco:

Exercer um poder simbólico não consiste meramente em acrescentar o ilusório a uma potência "real", mas sim em duplicar e reforçar a dominação efetiva pela apropriação dos símbolos e garantir a obediência pela conjugação das relações de sentido e poderio. (BACZKO, 1985, p. 298)

A partir desse referencial teórico, observamos a importância da mídia audiovisual ao estabelecer sistemas simbólicos capazes de interferir na sociedade. Não defendo que o Abertura tenha sido responsável por uma influência de largo espectro na sociedade brasileira, criando um imaginário da abertura política, aliás, missão de difícil constatação. O programa, motivado pelo espírito da abertura, auxiliou nesse processo de forma direta, apesar de não atingir um grande público. No entanto, alguns setores da classe média, intelectuais, sindicalistas e estudantes passaram a comentá-lo e a discutir as ideias de redemocratização. Assim, o debate sobre o fim do regime ganhou reforço.

A repercussão do programa na imprensa revela a força e expectativa criada com as primeiras edições, ainda em fevereiro de 1979, com a volta de grandes personalidades tradicionais da intelectualidade brasileira, como relata a crítica de televisão do jornal Folha de São Paulo, Helena Silveira:

Esse Abertura da Tupi, após o programa Flávio Cavalcanti, foi mesmo como o nome indica. (...) Ouvir mestre Alceu Amoroso Lima, como ouvira falar certa feita, no auditório da "Folha" deve ter dado a muita gente um passaporte de esperança que andava trancafiado para os brasileiros. Sem dúvida alguma, Abertura é uma nova proposta do gênero, que de 64 para cá andava relativamente capenga et por cause... ${ }^{32}$

\footnotetext{
${ }^{32}$ SILVEIRA, Helena. Domingo tem Abertura na Tupi. Helena Silveira vê TV, Ilustrada, Folha de São Paulo,
} 
Atribuir ao programa a responsabilidade de gerar esperança para os telespectadores ao trazer figuras da intelectualidade há muito tempo silenciadas é reconhecer o papel democrático do Abertura. O entusiasmo da jornalista não caiu na bajulação banal, consciente da importância em manter na televisão um programa de resgate de valores democráticos, ela alerta para que isso não fosse uma experiência efêmera, mas que tivesse continuidade:

Enfim, que não fique esse telejornal dos domingos dormindo sob o louro das primeiras apresentações é o que deseja um público tão faminto de informações televisivas, de debates e reportagens que possam ir até a face oculta do nosso mundo político, mais oculta, mesmo, que a face da lua só vista por Deus e pelos astronautas. Que venham informações de todos os quadrantes. Que se saiba da mortalidade da criança brasileira com cifras exatas. Que se penetre no tenebroso mundo do cárcere. Enfim que o Brasil possa semanalmente ser-nos oferecidos com suas contradições, suas ambiguidades e com seu povo: ricos, pobres, paupérrimos. Uma abertura sobre outra abertura. E que a última não seja somente a dos zipers engonçados. ${ }^{33}$

A expectativa criada era de que o programa tocasse em questões antes condenadas pelo regime. A miséria, as contradições, as várias classes sociais deveriam aparecer na televisão. A concretização do desejo da jornalista pode ser considerada em parte. Não observei ao longo do material estudado nenhuma menção direta a esses temas que eram motivo de análise na medida em que se falava sobre a volta dos exilados, de eleições e da democracia no seu estado pleno. Os problemas sociais em alguns quadros como no de Ziraldo, João Saldanha e Fausto Wolf eram abordados.

O jornalista Nei Duclós, também percebeu o Abertura de uma forma bastante positiva ao afirmar que o programa "abriu um claro na nojenta programação dos fins de semana onde somos assaltados por Silvio Santos e seus imitadores, pelo acusador Flávio Cavalcanti e pelas reportagens neuróticas, oportunistas e 'medicinais' do Fantástico."34 O Abertura se tornava, segundo o jornalista, a grande alternativa de programação daquele momento, mas a maior mudança estava no formato do programa com uma postura descontraída:

São Paulo, 16/02/1979, p. 44.

33 SILVEIRA, Helena. Domingo tem Abertura na Tupi. Helena Silveira vê TV, Ilustrada, Folha de São Paulo, São Paulo, 16/02/1979, p. 44.

${ }^{34}$ DUCLÓS, Nei. “Abertura” diante do espelho. Ilustrada, Folha de São Paulo, São Paulo, 28/06/1979, p. 46. 
O mais importante do Abertura é que ele retirou a gravata da televisão, aproximando o veículo do telespectador. Isso implica numa ousadia pouco comum aos outros programas, mais preocupados de mostrar a realidade de uma maneira Standar e falsa. A linguagem extremamente descontraída representa um avanço não oficial para a própria abertura política, o que é muito saudável, já que muitos preferem ficar desconfiando da democracia que está por vir em vez de trabalhar por ela. ${ }^{35}$

A opinião da imprensa não foi unânime em relação ao programa de Fernando Barbosa Lima. O jornalista O. C. Louzada Filho emitiu críticas que ajudam a pensar o Abertura e sua intenção de ser o grande baluarte, propagador das lutas democráticas. Apesar de reconhecer as boas intenções da equipe em propor valores democráticos com guia condutor, faz uma crítica à pretensa pluralidade que gerava certa confusão ao misturar os elementos diversos:

A intenção realmente é muito boa. Mais que isso: pretende-se democrática. Afinal, a não ser em nome da democracia, como justificar tanto tempo gasto com depoimento de tanta gente prestado a nós? Mas a verdade é que, diante desta Abertura, ficamos confusos. Tanta coisa muito importante ao fútil, misturado em tão pouco tempo, num ritmo tão rápido. Não chega nos fartar. No bom sentido, a sensação acaba sendo de confusão, de uma salada indigesta na qual o tempero, dos belos rostos e vestimentas ao fundo musical, predomina o essencial. Uma sensação de confusão que parece afirmar que qualquer abertura é confusa. O que, obviamente, não é verdade. Trata-se de uma questão de organização. (...) No fundo o resultado do programa é confuso. Não é de supor que pretendesse sê-lo: Afinal, Abertura leva a sério o seu título. Mas parece se basear num pressuposto, afinal preconceito de muitos hoje em dia, segundo o qual basta deixar falar qualquer um o que bem entende para que sejamos democráticos. Ora essa posição liberal é no mínimo aristocrática. (...) Ao final, o programa faz seu resumo. E o resumo reflete bem a relatividade do Abertura. Através da rápida gargalhada que mistura ministros, metalúrgicos, cantores, cineastas, falas e tiques. A informalidade não significa democracia: é sua caricatura. ${ }^{36}$

A crítica voraz acerta pontos que o programa defende como emblemáticos. Começa por mencionar o movimento de um programa que vai da discussão de temas

\footnotetext{
${ }^{35}$ DUCLÓS, Nei. “Abertura” diante do espelho. Ilustrada, Folha de São Paulo, São Paulo, 28/06/1979, p. 46.

36 LOUZADA FILHO, O. C. A “Abertura” equívoca no Canal 4. Ilustrada, Folha de São Paulo, São Paulo, 20/03/1979, p. 36.
} 

quadro de Antônio Guerreiro bem exemplifica essa questão, mas de forma inversa. A intenção dos produtores era exatamente mostrar que por trás da beleza física também tem um cabeça pensando sobre o Brasil e o mundo. ${ }^{37}$ Mas nenhuma outra crítica foi tão enfática quanto à questão do pluralismo do programa. A "sensação de confusão" que o jornalista afirma sentir fere a proposta central de garantir que muitas vozes fossem ouvidas. O que para Helena Silveira era uma das grandes qualidades do Abertura, no olhar de Louzada era problema por gerar confusão. Arriscou dizer que a falha, talvez, estivesse na condução do programa, fazendo alusão à má direção que não saberia fazer escolhas certas para manter a harmonia que foi, como vimos anteriormente, negada pelo diretor Fernando Barbosa Lima. O ponto de reflexão final assinalado remete ao resumo do fim do programa, visto como o momento da confusão maior. O tom informal que aparecia na proposta inicial do programa como um fator de inovação, é visto como uma caricatura de democracia.

O programa se esforçou no sentido de tentar influenciar na história como um agente de construção de memória. A memória coletiva é, segundo Jacques Le Goff (1990), alvo de manipulação e o interesse por ela é incontestável, seja no âmbito privado ou no público. Possuir os mecanismos de controle da memória e mesmo de poder ocultála ou gerar seu esquecimento é ter em mãos um arsenal de dominação de real poder. $O$ caráter seletivo da memória é capaz de preservar imagens positivas graças à afetividade que elas provocam. É por esse prisma que podemos compreender a estratégia de reforço de uma memória coletiva, a partir do resgate da memória individual. Evocando memórias individuais de um grupo, estamos criando, segundo Le Goff, uma memória coletiva, mas acima de tudo provocamos as condições para efetiva existência da identidade do seu duplo aspecto, individual e coletivo. A identidade coletiva também é parte do potencial da memória. Resgatar as falas dos integrantes do Abertura é uma forma de entender, a partir de um olhar não isento, como a equipe de articulistas percebiam suas atuações e

\footnotetext{
37 Programa Abertura, Rede Tupi, Tarcísio Holanda, Rio de Janeiro, março de 1979.
} 
até como o programa tentou se fixar na memória a partir da construção de um discurso em que o presente visava alcançar o futuro. A fala do apresentador Luiz Jatobá, ao final de uma edição do programa, exemplifica a forma como se procurava uma identificação com o público: "Abertura, democracia, um Brasil livre para brasileiros livres. Um programa de quem sabe, como você, compreender o mundo de hoje e ver o mundo de amanhã. Boa noite!"138

A proposta de imparcialidade do programa também ficou expressa em seus editoriais: "Severo Gomes, Rischbieter, Adolfo de Oliveira Franco, Ivete Vargas, Pedro Nava. Darcy Ribeiro. Esse é o espírito de Abertura. Esse é o espírito da democracia. Não importa de que lado você esteja." 39

Os editoriais do programa Abertura são exemplos de afirmação dos ideais da proposta de Fernando Barbosa Lima e sua equipe e, no entanto, demarcam outras intenções como a de firmar no imaginário a ideia de que o programa estaria desempenhando, ao valorizar a ideia de que seria "o fim do silêncio", um papel histórico. Era a tentativa da construção de uma memória a partir da glorificação de uma autoimagem, preparando em cada edição os elementos visuais pelos quais o programa deveria ser lembrado.

A fala de que o Abertura surgia em um momento importante da história brasileira e seria um dos grandes agentes da redemocratização no Brasil pareceu, para Louzada Filho, revestido de exagero:

O Abertura, entretanto, cria tanta expectativa no telespectador que os seus poucos defeitos acabam se transformando em verdadeiras torturas. Um desses defeitos é o excessivo narcisismo que tomou conta de todos. A começar pelo apresentador que sempre está fazendo propaganda do programa. Sempre tem alguém repetindo que "o Abertura está revolucionando a televisão brasileira", numa euforia prejudicial. ${ }^{40}$

\footnotetext{
${ }^{38}$ Programa Abertura, Rede Tupi, Luiz Jatobá, Rio de Janeiro, março de 1979.

39 Programa Abertura, Rede Tupi, Luiz Jatobá, Rio de Janeiro, março de 1979.

40 LOUZADA FILHO, O. C. A “Abertura” equívoca no Canal 4. Ilustrada, Folha de São Paulo, São Paulo, 20/03/1979.
} 
A autoexaltação está amparada numa jogada de marketing visando aumentar a audiência, porque não se pode esperar que um empreendimento como esse esteja apenas no entusiasmo da equipe do Abertura, na crença de que a ditadura estava prestes a acabar. O Abertura tentava criar uma empatia com o público num jogo de reconhecimento quase pessoal, como se fosse possível falar com o público olho no olho e com a pretensão de passar para o telespectador a segurança de quem fala a "verdade, a verdade de cada um, a verdade de frente, dentro dos olhos." 41

\section{Considerações finais}

A fórmula durou 15 meses e sete dias. O programa que surgira com grande entusiasmo no dia 4 de fevereiro de 1979, teve sua última edição em 11 de maio de 1980. A precária infraestrutura de sua emissora transmissora, a Tupi, que tinha sérias dificuldades para se manter no ar, não foi o único problema enfrentado. O interesse dos patrocinadores desapareceu quando o programa deixou de ter o ar combativo diferenciado de seu primeiro ano de transmissão. Apesar de questões técnicas e financeiras, o maior entrave para sua permanência foi o esvaziamento temático. As grandes bandeiras defendidas perderam sua razão de ser na medida em que o governo efetivava seu projeto de reformas políticas. Com a anistia em vigor, a reformulação partidária e o gradual aumento das liberdades democráticas, não totalmente concretizadas, mas em ritmo de implantação e com as vozes antes caladas se expondo em outros programas, o Abertura tinha pouco a dizer. As últimas edições valiam-se de repetição de quadros passados e pouco acrescentavam ao debate do momento. Esse empobrecimento da proposta refletiu na diminuição de audiência, sendo superado pelos "enlatados e concertos internacionais" da Rede Globo e, até mesmo, pelo Homem do sapato branco, da TVS, de Silvio Santos. Fernando Barbosa Lima considera que o Abertura "aos poucos seria tão destruído que acabaria esclerosado"42, daí a decisão de encerrar a produção do programa.

\footnotetext{
${ }^{41}$ Programa Abertura, Rede Tupi, Editorial, Rio de Janeiro, abril de 1980.

${ }^{42}$ VEJA, 21 de maio de 1980, p. 62.
} 
A experiência do Abertura leva à reflexão de que a televisão pode e deve manter uma relação mais direta com a sociedade. O discurso pró-liberalização do Abertura não atingia a todos, não alcançava o trabalhador devido ao horário. Mesmo assim, o trabalho realizado deve ser reconhecido como exemplo de trabalho autônomo no qual os seus integrantes conseguiram, apesar do monitoramento, discorrer sobre a temática central proposta, atuando sem a pressão do proprietário, pois como produção independente que era, não estava sujeita às determinações da Rede Tupi, mas do idealizador Fernando Barbosa Lima que avalizou o trabalho realizado.

A memória construída diz muito sobre o seu presente, "O fim do silêncio", "jornalismo de verdade", "Um programa para quem vê o Brasil de hoje e pensa no amanhã". Essa frases fizeram parte do Abertura e representam o esforço de Fernando Barbosa Lima de não perder a chance histórica de fazer a diferença no exato momento em que ditadura começava a decair. "O Fernando sabia o que o programa representava naquele momento. A ditadura ia acabar, por isso ele chamou o pessoal". ${ }^{43} \mathrm{O}$ depoimento de Sérgio Cabral dá o tom para o entendimento que o produtor fazia do programa. A expectativa de a liberalização levar à democracia fez com que o produtor conduzisse seu trabalho em cada quadro, cada fala, por mais independente que fosse; tivesse nas mãos dele, como editor final, o exato lugar na composição de um discurso de abertura que visava ter um lugar na memória. Invocando o passado na abertura do programa, discutindo o presente no seu desenvolvimento, resgatava no final de cada edição o discurso de um futuro de democracia no qual o Abertura seria, na televisão, também um de seus responsáveis. O objetivo pretensioso se cumpriu? Roberto D'Avila afirma que sim. "O Abertura era o Fernando, e cada um de nós que participou com ele desse projeto ajudou na luta pelo fim da ditadura." 44 Um dos grandes méritos dessa iniciativa foi, não apenas retratar a cada semana as discussões em torno da volta das liberdades democráticas, mas mostrar a necessidade, através da fala dos apresentadores, entrevistados e colaboradores, da rápida ação do governo, de restaurar os princípios democráticos.

\footnotetext{
${ }^{43}$ CABRAL, Sérgio, 23/10/2013, Rio de Janeiro. Entrevista concedida a Paulo Roberto de Azevedo Maia.

${ }^{44}$ D'AVILA, Roberto, 25/01/2014, Rio de Janeiro. Entrevista concedida a Paulo Roberto de Azevedo Maia.
} 


\section{Referências}

ADORNO, Theodore. Educação e emancipação. Rio de Janeiro: Editora Paz e Terra, 2001.

AR AÚJO, Maria Paula Nascimento. A luta democrática contra o regime militar na década de 1970. In: REIS FILHO, Daniel; RIDENTI, Marcelo; SÁ MOTTA, Rodrigo Patto. O golpe e a ditadura militar - 40 anos depois (1964-2004). Bauru (SP): Edusc, 2004.

BACZKO, Bronislaw. Imaginação social. , In ROMANO, Ruggiero (Org.). Enciclopédia Einaudi, vol. 5. Anthropos - Homem. Lisboa: Imprensa/Casa da Moeda, 1985.

CABRAL, Sérgio, 23/10/2013, Rio de Janeiro. Entrevista concedida a Paulo Roberto de Azevedo Maia.

CARMO, Paulo Sérgio. Culturas da rebeldia: a juventude em questão. São Paulo: Editora SENAC, 2000.

DUCLÓS, Nei. “Abertura” diante do espelho. Ilustrada, Folha de São Paulo, São Paulo, 28/06/1979

HALL, Stuart. Codificação/decodificação: Da diáspora: identidades e mediações culturais. Belo Horizonte: Editora UFMG, 2003.

SILVEIRA, Helena. Domingo tem Abertura na Tupi. Helena Silveira vê TV, Ilustrada, Folha de São Paulo, São Paulo, 16/02/1979.

LEITE FILHO, FC. El Caudillo: Leonel Brizola - um perfil biográfico. São Paulo: Aquariana, 2008.

LIMA, Fernando Barbosa. Nossas câmeras são seus olhos. Rio de Janeiro: Ediouro, 2007.

LOUZADA FILHO, O. C. A “Abertura” equívoca no Canal 4. Ilustrada, Folha de São Paulo, São Paulo, 20/03/1979.

MAIA, Paulo Roberto de Azevedo. Abertura: televisão e a luta pela democracia no Brasil (1979-1980). 2014. Tese (Doutorado em História) - Universidade Federal Fluminense, Departamento de história , Niterói, 2014.

MEZAROBBA, Glenda. Um acerto de conta com o futuro: A anistia e suas consequências: um estudo do caso brasileiro. São Paulo: Associação Editorial Humanitas, FAPESP, 2006. 
PORTO, Mauro Pereira. A pesquisa sobre a recepção e os efeitos da mídia: propondo um enfoque integrado. In: CONGRESSO BRASILEIRO DE CIÊNCIAS DA COMUNICAÇÃO. INTERCOM, Belo Horizonte, XXVI, MG. 2-6, set. 2003. Anais..., Belo Horizonte, 2003

REIS FILHO, Daniel Aarão. Ditadura militar, esquerdas e sociedade. $2^{\underline{a}}$ edição. Rio de Janeiro: Jorge Zahar, 2002.

RESENDE, Guilherme Jorge de. Telejornalismo no Brasil: um perfil editorial. São Paulo: Summus, 2000.

RIBEIRO, Santuza Naves. BOTELHO, Isaura. A televisão e a política de integração nacional. In: NOVAES, Adauto (org.). Anos 70, Ainda sob a tempestade. Rio de Janeiro: Aeroplano Editora, SENAC Rio, 2005.

ROLLEMBERG, Denise. Exílio: entre raízes e radares. Rio de Janeiro: Editora Record, 1999.

SERRA, Paulo. 2008. Estética e media - o caso da televisão. In: Biblioteca Online das Ciências da Comunicação. Disponível em: <http://www.bocc.ubi.pt/pag/serra-pauloestetica-media.pdf>. Acesso em: 03/11/2012.

SILVEIRA, Helena. Domingo tem Abertura na Tupi. Helena Silveira vê TV, Ilustrada, Folha de São Paulo, São Paulo, 16/02/1979, p. 44.

SILVA, Patricia Alves do Rego. TV Tupi, a pioneira na América do Sul. Rio de Janeiro: Prefeitura da Cidade do Rio de Janeiro: Secretaria Especial de Comunicação Social, 2004. Disponível em: <http://www.rio.rj.gov.br/arquivo/pdf/cadernos_comunicacao/memoria/memoria11.pdf> Acesso em: 08/06/2013.

SOUZA, José Carlos Aronchi de. Gêneros e formatos na televisão brasileira. São Paulo: Summus Editorial, 2004.

TELES, Edson; SAFATLE, Vladimir Pinheiro. 0 que resta da ditadura: a exceção brasileira. São Paulo, Boitempo Editorial, 2015.

VIZEU, Carlos Alberto, Rio de Janeiro, 19/03/2011. Entrevista concedida a Paulo Roberto de Azevedo Maia. 
Recebido em 28/02/2017 Aprovado em 03/07/2017

Universidade do Estado de Santa Catarina - UDESC

Programa de Pós-Graduação em História - PPGH

Revista Tempo e Argumento

Volume 09 - Número 21 - Ano 2017

tempoeargumento@gmail.com 